\title{
HYPERGLOBULINAEMIA IN RHEUMATOID ARTHRITIS ITS RELATIONSHIP WITH DISEASE ACTIVITY AND ITS CHANGES UNDER ADRENOCORTICAL TREATMENT
}

\author{
BY \\ L. BONOMO* \\ From the Rheumatism Department West London Hospital
}

(RECEIVED FOR PUBLICATION MARCH 4, 1957)

Hyperglobulinaemia is a fundamental characteristic of rheumatoid arthritis, and is also found in other collagen diseases. It is said to demonstrate the hyperactivity of the reticulo-endothelial system shown by the hyperplasia of its medullary elements (Marmont, 1948; Curletto and Magistretti, 1949). In the course of studying this hyperglobulinaemia by paper electrophoresis, an increase has been observed in the alpha and gamma globulin fractions (Olhagen, 1952; Wallis, 1950; Ropes, Perlmann, Kaufman, and Bauer, 1954; Jacqueline, de Traverse, and Besson, 1954; Hunt and Trew, 1954), or in the beta-gamma globulin fractions (Layani, Bengui, and de Mende, 1952). An increase in the alpha-2 globulin is considered to be characteristic of the first phase of rheumatoid disease, associated with inflammatory-exudative changes; an increase in gamma globulin generally appears later, together with a reactionary fibrosis (Olhagen, 1952; Ropes and others, 1954; Layani and others, 1952; Jacqueline and others, 1954). In exceptionally serious cases, a conspicuous increase in the gamma globulin fraction and a moderate increase in the alpha globulin fraction (Olhagen, 1952), or a persistently raised gamma-1 globulin (Layani and others, 1952), have been observed.

During the hormone therapy of rheumatoid arthritis, a decrease has been noted in the alpha globulins (particularly alpha-2), and especially in the gamma globulins in cases which were progressing favourably (Wallis, 1950; Villa, Ballabio, and Sala, 1953; Layani and others, 1952; Ropes and others, 1954). After an initial decrease in the medullary reticulo-endothelial hyperplasia, the electrophoretic pattern and the sero-agglutinating titres returned to normal (Berglund, Nordenson, and Olhagen, 1951). Similar electrophoretic changes

* Assistant at the Department of Internal Medicine, Bari University, Italy (Director: Prof. V. Chini). were recorded in patients with rheumatic fever (Van Leeuwen, Kelly, and Jackson, 1955) and disseminated lupus erythematosus (Reiner, 1950) who were undergoing hormone therapy.

The present investigation was designed to show how the serum protein changes corresponded with disease activity (assessed by painful joints, fever, loss of weight, anaemia, and the erythrocyte sedimentation rate), and their relation to treatment with cortisone, $\mathrm{ACTH}$, and prednisone.

The changes observed in cases resistant to hormone treatment or with a high degree of disease activity have enabled certain suggestions to be made concerning the pathogenesis of rheumatoid arthritis:

\section{Methods}

The electrophoretic determinations were made with a Shandon apparatus, by the method of Flynn and De Mayo (1951), using Whatman paper No. $1(5 \cdot 35)$, with $0.01 \mathrm{ml}$. serum for every $2.5 \mathrm{~cm}$., and a veronal

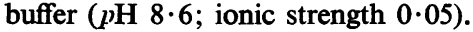

The separation was carried out overnight during a period of $16 \mathrm{hrs}$ with a current of $6 \mathrm{v} / \mathrm{cm}$.

The strips were then put into an oven for $30 \mathrm{~min}$. at $100^{\circ} \mathrm{C}$. and stained for $10 \mathrm{~min}$. with a solution of 0.2 per cent. Lissamine green S.F. 150 (I.C.I.) in water containing 25 per cent. ethanol and 5 per cent. acetic acid. The strips were then rinsed in tap water containing 2 per cent. acetic acid until the background became colourless and were finally dried in an oven for $10 \mathrm{~min}$. at $100^{\circ} \mathrm{C}$.

The scanning was done with an electrodensitometer. The various protein groups, measured by planimetry of the electrophoretic pattern after extrapolating each curve, were expressed as percentages of the total protein estimated by the Biuret method (Wolfson, Cohn, Calvary, and Ichiba, 1948).

To check the accuracy of the method, two blood samples were taken from the same normal subject on two successive days, and five electrophoretic determinations were made on each sample after the serum had been kept in a refrigerator overnight. The mean values and 
standard deviations of individual protein groups are shown in Table $I$.

TABLE I

AVERAGE RESULTS OF TEN DETERMINATIONS ON SAMPLES FROM A NORMAL SUBJECT

\begin{tabular}{|c|c|c|c|c|c|}
\hline \multirow{2}{*}{$\underset{\text { (per cent.) }}{\text { Albumin }}$} & \multicolumn{5}{|c|}{ Globulin (per cent.) } \\
\hline & $\alpha 1$ & $\alpha 2$ & $\beta$ & $\gamma 1$ & $\gamma^{2}$ \\
\hline S.D. $2 \cdot 8$ & $\begin{array}{l}1.9 \\
0.72\end{array}$ & $\begin{array}{l}7 \cdot 7 \\
0.93\end{array}$ & $\begin{array}{l}9 \cdot 6 \\
0 \cdot 75\end{array}$ & $\begin{array}{l}1.7 \\
0.75\end{array}$ & $\begin{array}{r}14 \cdot 1 \\
1 \cdot 46\end{array}$ \\
\hline
\end{tabular}

Table II shows the mean values in ten normal subjects as percentages of total serum protein, together with the albumin-globulin ratio $(\mathrm{A} / \mathrm{G})$; the average total protein was $7 \cdot 5 \mathrm{~g} . / 100 \mathrm{ml}$.

TABLE II

MEAN VALUES IN TEN NORMAL SUBJECTS

Results from seven osteo-arthritic patients (Table III) showed no abnormalities; the average total protein was $6.9 \mathrm{~g} . / 100 \mathrm{ml}$.

TABLE III

MEAN VALUES IN SEVEN OSTEO-ARTHRITIC PATIENTS

\begin{tabular}{|c|c|c|c|c|c|c|c|}
\hline \multirow{2}{*}{$\begin{array}{l}\text { Albumin } \\
\text { (per cent.) }\end{array}$} & \multicolumn{5}{|c|}{ Globulin (per cent.) } & \multirow{2}{*}{$\mathbf{A} / \mathbf{G}$} & \multirow{2}{*}{$\begin{array}{c}\text { Total } \\
\text { Protein } \\
\text { (g./100 ml.) }\end{array}$} \\
\hline & $\alpha 1$ & $\alpha 2$ & $B$ & $\gamma 1$ & $\gamma 2$ & & \\
\hline $64 \cdot 3$ & $2 \cdot 4$ & $7 \cdot 9$ & $9 \cdot 4$ & $1 \cdot 9$ & $14 \cdot 1$ & \multirow{2}{*}{$1 \cdot 8$} & \multirow{2}{*}{$6 \cdot 9$} \\
\hline S.D. $1 \cdot 55$ & $0 \cdot 7$ & 1 & $2 \cdot 1$ & $0 \cdot 7$ & $1 \cdot 1$ & & \\
\hline
\end{tabular}

\section{Material}

Altogether 153 electrophoretic determinations were carried out on the serum of 56 patients with various

\begin{tabular}{|c|c|c|c|c|c|c|c|}
\hline \multirow{2}{*}{$\begin{array}{c}\text { Albumin } \\
\text { (per cent.) }\end{array}$} & \multicolumn{5}{|c|}{ Globulin (per cent.) } & \multirow{2}{*}{$A / G$} & \multirow{2}{*}{$\begin{array}{c}\text { Total } \\
\text { Protein } \\
\text { (g./100 ml.) }\end{array}$} \\
\hline & $\alpha 1$ & $\alpha 2$ & $B$ & $\gamma 1$ & $\gamma 2$ & & \\
\hline $65 \cdot 8$ & 2 & $7 \cdot 2$ & $9 \cdot 9$ & $1 \cdot 9$ & $13 \cdot 2$ & \multirow{2}{*}{$-1 \cdot 92$} & \multirow{2}{*}{$7 \cdot 5$} \\
\hline S.D. $3 \cdot 8$ & $0 \cdot 76$ & $1 \cdot 36$ & 1.41 & $1 \cdot 22$ & $2 \cdot 9$ & & \\
\hline
\end{tabular}

clinical types of rheumatoid arthritis, and of one patient with ankylosing spondylitis (Case 8, Table VII).

The majority were in-patients or out-patients at the West London Hospital, and the remainder were patients at the Hospital of St. John and St. Elizabeth. The 57 patients included 41 women and sixteen men. The duration of disease ranged from a few months to 17 years (mean $6 \frac{1}{2}$ yrs).

Nineteen patients had either never had treatment or had had nothing but analgesics for a long time, three were having gold therapy, and two phenylbutazone. 33 had received long-term ACTH, cortisone, or prednisone for varying periods, and three others began hormone therapy during the investigation.

\section{Results}

On the basis of the A/G ratio, 52 of the rheumatoid patients were divided into three groups (Table IV).

Group I (A/G ratio only slightly reduced $(>1 \cdot 4)$ with moderate serum protein changes).-The alpha-2 and gamma-2 globulin fractions were increased. Some recent cases (onset of disease within 3 years) were found in this group, but most of them were cases of longer duration with slight disease activity controlled by treatment. 35 per cent. had a history of more than 9 years' duration (Table V, 20 patients, overleaf).

Group II (A/G ratio markedly reduced or reversed $(>0.85))$. - Marked increases were seen in the globulin fractions, being most marked in the gamma-2, appreciable in the alpha (especially alpha-2), and slight in the beta and gamma-1. A greater number of recent cases was found in this group (Table VI, 19 patients, overleaf).

Group III (A/G ratio markedly reversed $(<0 \cdot 85)$ ). -A marked fall in albumin was accompanied by a rise in the alpha-2 and particularly in the gamma-2 fractions, the mean value of the latter being three

TABLE IV

MEAN ELECTROPHORETIC VALUES IN 52 CASES OF RHEUMATOID ARTHRITIS

\begin{tabular}{|c|c|c|c|c|c|c|c|c|}
\hline \multirow{2}{*}{ Group } & \multirow{2}{*}{$\begin{array}{l}\text { No. of } \\
\text { Patients }\end{array}$} & \multirow{2}{*}{$\begin{array}{l}\text { Albumin } \\
\text { (Per cent.) }\end{array}$} & \multicolumn{5}{|c|}{ Globulin (Per cent.) } & \multirow{2}{*}{$\underset{\text { Ratio }}{\text { Albumin/Globulin }}$} \\
\hline & & & $\alpha 1$ & $\alpha 2$ & $\beta$ & $\gamma 1$ & $\gamma 2$ & \\
\hline I & 20 & $\begin{array}{r}61 \cdot 3 \\
\text { S.D. } 5 \cdot 29\end{array}$ & $\begin{array}{l}2 \cdot 3 \\
0 \cdot 83\end{array}$ & $\begin{array}{l}9 \cdot 7 \\
1 \cdot 87\end{array}$ & $\begin{array}{r}10 \cdot 2 \\
1 \cdot 0\end{array}$ & $\begin{array}{l}1 \cdot 9 \\
0 \cdot 77\end{array}$ & $\begin{array}{l}14 \cdot 6 \\
4 \cdot 50\end{array}$ & $1 \cdot 58$ \\
\hline II & 19 & $\begin{array}{r}52 \cdot 4 \\
\text { S.D. } 3 \cdot 57\end{array}$ & $\begin{array}{l}3 \cdot 3 \\
1 \cdot 04\end{array}$ & $\begin{array}{l}10 \cdot 7 \\
3 \cdot 06\end{array}$ & $\begin{array}{l}12 \\
2 \cdot 23\end{array}$ & $\begin{array}{l}3 \\
1 \cdot 70\end{array}$ & $\begin{array}{l}18 \cdot 6 \\
4 \cdot 74\end{array}$ & $1 \cdot 10$ \\
\hline III & 13 & $\begin{array}{r}38 \cdot 7 \\
\text { S.D. } 4 \cdot 73\end{array}$ & $\begin{array}{l}3 \cdot 7 \\
1 \cdot 65\end{array}$ & $\begin{array}{l}13 \cdot 4 \\
3 \cdot 82\end{array}$ & $\begin{array}{l}12 \\
1 \cdot 94\end{array}$ & $\begin{array}{l}3 \cdot 4 \\
1 \cdot 48\end{array}$ & $\begin{array}{r}28 \cdot 8 \\
6 \cdot 34\end{array}$ & 0.64 \\
\hline
\end{tabular}


TABLE V

RESULTS OF ELECTROPHORESIS IN TWENTY PATIENTS IN GROUP I

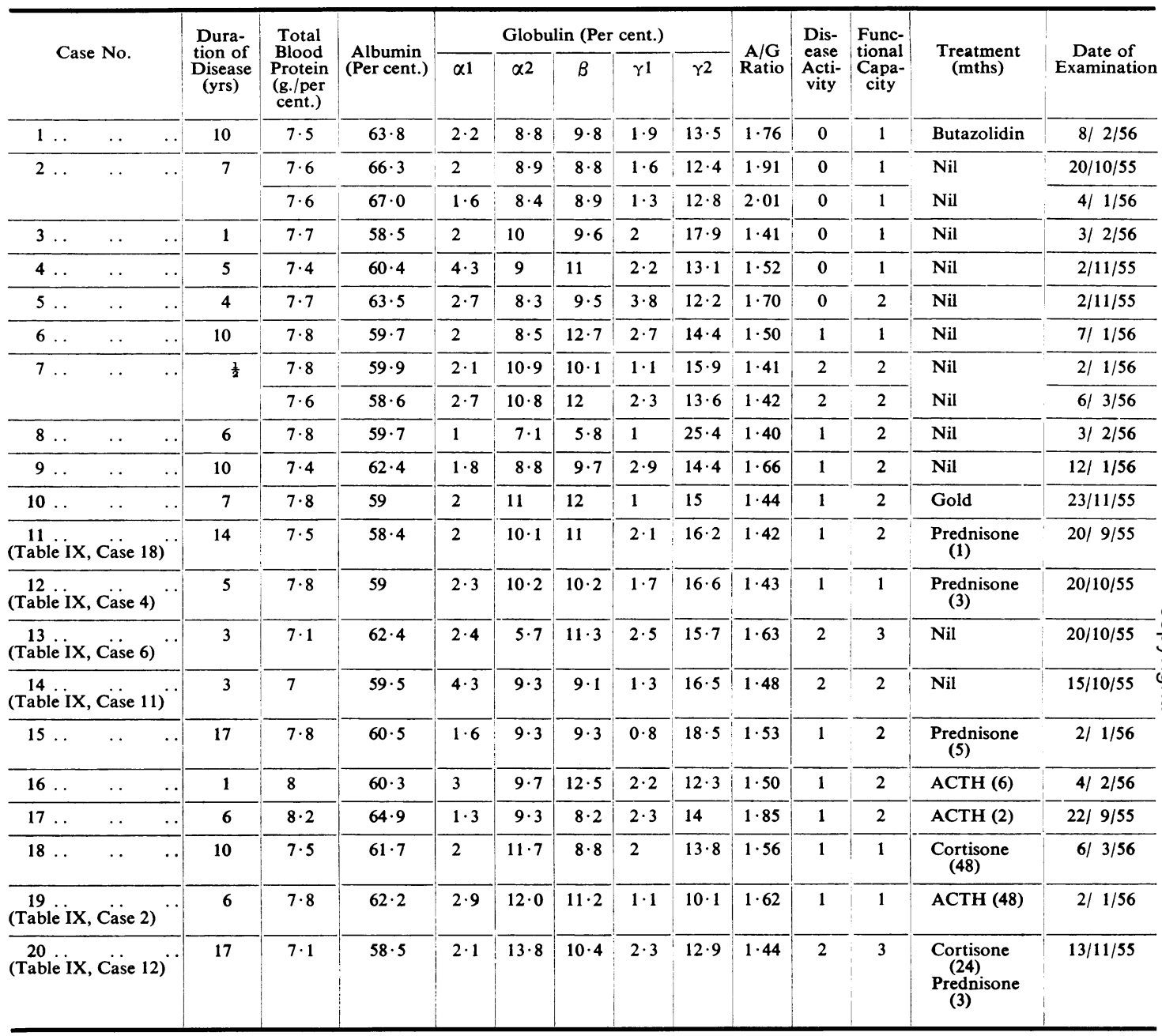

times the normal average. Recent cases were most frequently found in this group; more than 50 per cent. had shown rheumatoid symptoms for less than 3 years (Table VII, 13 patients, opposite).

Changes in the total serum protein levels were not remarkable, but decreased albumin fractions with increased alpha-2 and gamma-2 globulin fractions appeared to be characteristic of rheumatoid disease, and to become more marked in the severer stages of the disease by increases almost exclusively in the gamma fraction, the mean gamma globulin value in Group III being double that in Group I.
Disease Activity.-The degree of disease activity was closely related to the serum protein changes (Table VIII, overleaf). Only 20 per cent. of Group I were cases with marked disease activity (Degree 2); 68 per cent. of Group II showed marked or high disease activity (Degree 2 or 3); and 92 per cent. of Group III showed marked or high disease activity (Degree 2 or 3).

Electrophoretic data may therefore be valuable in the assessment of disease activity and consequently in prognosis. Some cases which had been clinically assessed as having only slight disease activity showed marked changes in the serum protein (Cases 
TABLES VI AND VII

RESULTS OF ELECTROPHORESIS IN 19 PATIENTS IN GROUP II (above) AND 13 PATIENTS IN GROUP III (below)

\begin{tabular}{|c|c|c|c|c|c|c|c|c|c|c|c|c|c|}
\hline \multirow{2}{*}{ Case No. } & \multirow{2}{*}{$\begin{array}{c}\text { Dura- } \\
\text { tion of } \\
\text { Disease } \\
\text { (yrs) }\end{array}$} & \multirow{2}{*}{$\begin{array}{l}\text { Total } \\
\text { Blood } \\
\text { Protein } \\
\text { (g./per } \\
\text { cent.) }\end{array}$} & \multirow{2}{*}{ Albumin } & \multicolumn{5}{|c|}{ Globulin (Per cent.) } & \multirow{2}{*}{$\begin{array}{c}\mathbf{A} / \mathbf{G} \\
\mathbf{R} \text { atio }\end{array}$} & \multirow{2}{*}{$\begin{array}{l}\text { Dis- } \\
\text { ease } \\
\text { Acti- } \\
\text { vity }\end{array}$} & \multirow{2}{*}{$\begin{array}{l}\text { Func- } \\
\text { tional } \\
\text { Capa- } \\
\text { city }\end{array}$} & \multirow{2}{*}{$\begin{array}{l}\text { Treatment } \\
\text { (mths) }\end{array}$} & \multirow{2}{*}{$\begin{array}{c}\text { Date of } \\
\text { Examination }\end{array}$} \\
\hline & & & & $\alpha 1$ & $\alpha 2$ & $B$ & $\gamma 1$ & $\gamma^{2}$ & & & & & \\
\hline $1 \ldots$ & 3 & $8 \cdot 2$ & $57 \cdot 5$ & $1 \cdot 6$ & $10 \cdot 5$ & 9 & $3 \cdot 2$ & $18 \cdot 2$ & $1 \cdot 35$ & 1 & 1 & Salicylate & $20 / 10 / 55$ \\
\hline $2 \ldots$ & 12 & $7 \cdot 8$ & 58 & $4 \cdot 6$ & $11 \cdot 6$ & $12 \cdot 2$ & $3 \cdot 8$ & $9 \cdot 8$ & $1 \cdot 38$ & 1 & 2 & ACTH (2) & $2 / 11 / 55$ \\
\hline (Table IX, Case 15) & 1 & $7 \cdot 8$ & $53 \cdot 7$ & $1 \cdot 3$ & $12 \cdot 8$ & $11 \cdot 9$ & 2 & $18 \cdot 3$ & $1 \cdot 13$ & 2 & 3 & АCTH (1) & $24 / 9 / 55$ \\
\hline (Table IX, Case 17) & 3 & 7 & $54 \cdot 8$ & $4 \cdot 2$ & $10 \cdot 3$ & $16 \cdot 3$ & $4 \cdot 2$ & $10 \cdot 2$ & $1 \cdot 20$ & 1 & 2 & Nil & $13 / 10 / 55$ \\
\hline $5 \ldots$ & $\frac{1}{2}$ & $8 \cdot 2$ & $57 \cdot 2$ & $4 \cdot 1$ & $12 \cdot 2$ & $9 \cdot 1$ & $1 \cdot 3$ & $16 \cdot 1$ & $1 \cdot 33$ & 2 & 3 & Nil & $8 / 12 / 55$ \\
\hline $6 \ldots$ & 10 & $8 \cdot 1$ & $56 \cdot 2$ & $2 \cdot 8$ & $7 \cdot 3$ & $10 \cdot 5$ & $1 \cdot 1$ & $22 \cdot 1$ & $1 \cdot 28$ & 2 & 2 & Nil & $8 / 2 / 56$ \\
\hline 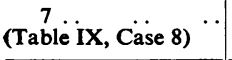 & 13 & $7 \cdot 1$ & $52 \cdot 5$ & $4 \cdot 2$ & $10 \cdot 3$ & $15 \cdot 3$ & $3 \cdot 1$ & $14 \cdot 6$ & $1 \cdot 10$ & 2 & 3 & ACTH (1) & $13 / 10 / 55$ \\
\hline $8 \ldots$ & 1 & $7 \cdot 9$ & $51 \cdot 5$ & $2 \cdot 1$ & 9 & 10 & $3 \cdot 2$ & $24 \cdot 2$ & $1 \cdot 06$ & 2 & 3 & Nil & $3 / 1 / 56$ \\
\hline $9 \ldots$ & 5 & $7 \cdot 6$ & 53 & $4 \cdot 2$ & $12 \cdot 3$ & $11 \cdot 2$ & $3 \cdot 2$ & $16 \cdot 1$ & $1 \cdot 13$ & 2 & 2 & Cortisone (36) & $20 / 10 / 55$ \\
\hline $10 \ldots$ & 3 & $7 \cdot 7$ & $53 \cdot 8$ & $2 \cdot 3$ & $10 \cdot 3$ & $10 \cdot 8$ & $2 \cdot 3$ & $20 \cdot 5$ & $1 \cdot 17$ & 2 & 2 & Cortisone (24) & $3 / 11 / 55$ \\
\hline $11 \ldots$ & 7 & $7 \cdot 3$ & 50 & $3 \cdot 6$ & $8 \cdot 8$ & $11 \cdot 3$ & $2 \cdot 4$ & $23 \cdot 9$ & 1 & 1 & 2 & Cortisone (36) & $8 / 3 / 56$ \\
\hline $12 \ldots$ & 5 & $8 \cdot 1$ & $51 \cdot 8$ & $4 \cdot 2$ & $9 \cdot 5$ & $9 \cdot 7$ & $2 \cdot 6$ & $22 \cdot 2$ & $1 \cdot 05$ & 2 & 1 & ACTH (36) & $8 / 2 / 56$ \\
\hline $13 \ldots$ & 8 & $8 \cdot 3$ & $51 \cdot 2$ & $3 \cdot 2$ & $6 \cdot 1$ & $7 \cdot 8$ & 2 & $29 \cdot 7$ & $1 \cdot 04$ & 2 & 2 & Nil & $4 / 2 / 56$ \\
\hline $\begin{array}{ll}\cdots & \end{array}$ & 4 & 8 & $54 \cdot 5$ & $4 \cdot 2$ & $8 \cdot 5$ & $13 \cdot 3$ & $2 \cdot 5$ & 17 & $1 \cdot 22$ & 1 & $\mathbf{0}$ & Gold & $2 / 11 / 55$ \\
\hline (Table IX, Case 7) & 6 & $7 \cdot 7$ & $46 \cdot 8$ & $3 \cdot 1$ & $9 \cdot 4$ & $15 \cdot 3$ & 6 & $19 \cdot 4$ & $0 \cdot 88$ & 1 & 2 & $\begin{array}{l}\text { Cortisone (48) } \\
\text { Prednisone (2) }\end{array}$ & $14 / 11 / 55$ \\
\hline $\begin{array}{c}16 \\
\text { (Table IX, Case 9) }\end{array}$ & 17 & 8 & $46 \cdot 9$ & $3 \cdot 9$ & $18 \cdot 2$ & $13 \cdot 8$ & $2 \cdot 1$ & $15 \cdot 1$ & 0.88 & 2 & 1 & ACTH (24) & $20 / 10 / 55$ \\
\hline (Table IX, Case 1) & 4 & $8 \cdot 2$ & $48 \cdot 5$ & $1 \cdot 8$ & $10 \cdot 8$ & $13 \cdot 1$ & $5 \cdot 1$ & $20 \cdot 7$ & 0.94 & 2 & 2 & $\begin{array}{l}\text { Cortisone (12) } \\
\text { Prednisone (1) }\end{array}$ & $15 / 9 / 55$ \\
\hline $18 \ldots$ & 8 & $7 \cdot 6$ & $46 \cdot 5$ & $3 \cdot 4$ & $15 \cdot 8$ & $12 \cdot 8$ & $4 \cdot 1$ & $17 \cdot 4$ & 0.87 & 2 & 2 & АCTH (24) & $23 / 11 / 55$ \\
\hline $19 \ldots$ & 15 & $7 \cdot 5$ & $49 \cdot 5$ & $3 \cdot 4$ & $9 \cdot 1$ & $11 \cdot 9$ & $2 \cdot 9$ & $23 \cdot 2$ & $0 \cdot 98$ & 3 & 2 & Cortisone (12) & $17 / 9 / 55$ \\
\hline (Table IX, Case 3) & 3 & $8 \cdot 2$ & $45 \cdot 4$ & 5 & $15 \cdot 2$ & 10 & $1 \cdot 9$ & $22 \cdot 5$ & 0.83 & 3 & 3 & $\begin{array}{l}\text { Cortisone (12) } \\
\text { Prednisone (3) }\end{array}$ & $13 / 10 / 55$ \\
\hline $2 \ldots$ & 3 & $8 \cdot 4$ & $43 \cdot 8$ & $4 \cdot 4$ & $16 \cdot 5$ & $13 \cdot 7$ & $2 \cdot 2$ & $19 \cdot 4$ & 0.79 & 2 & 2 & Gold & $4 / 10 / 55$ \\
\hline $3 \ldots \quad \ldots$ & 1 & $8 \cdot 3$ & $42 \cdot 9$ & $4 \cdot 2$ & $7 \cdot 4$ & $11 \cdot 5$ & $3 \cdot 3$ & $30 \cdot 7$ & 0.75 & 2 & 2 & ACTH (3) & $6 / 10 / 55$ \\
\hline $4 \ldots \quad \ldots$ & 13 & $7 \cdot 9$ & $42 \cdot 7$ & 2 & $8 \cdot 7$ & $8 \cdot 6$ & $2 \cdot 4$ & $35 \cdot 6$ & 0.75 & 2 & 2 & Nil & $3 / 11 / 55$ \\
\hline $5 \ldots \quad \ldots$ & 8 & $7 \cdot 7$ & $41 \cdot 2$ & $3 \cdot 1$ & $15 \cdot 3$ & $14 \cdot 2$ & $2 \cdot 8$ & $23 \cdot 4$ & $0 \cdot 70$ & 1 & 1 & $\begin{array}{c}\text { Cortisone and } \\
\text { ACTH (48) } \\
\text { Prednisone (2) } \\
\end{array}$ & $20 / 10 / 55$ \\
\hline $6 \ldots$ & 6 & $7 \cdot 9$ & $41 \cdot 3$ & $3 \cdot 2$ & $19 \cdot 8$ & $10 \cdot 7$ & $1 \cdot 2$ & $23 \cdot 8$ & $0 \cdot 70$ & 2 & 2 & Butazolidin & $30 / 11 / 55$ \\
\hline $\begin{array}{c}7 \text { (Fig. 4) } \\
\text { (Table IX, Case 13) }\end{array}$ & 17 & $7 \cdot 7$ & $40 \cdot 3$ & 2 & $9 \cdot 9$ & $8 \cdot 7$ & $5 \cdot 3$ & $33 \cdot 8$ & 0.67 & 3 & 2 & Cortisone (24) & $6 / 10 / 55$ \\
\hline $8 \ldots$ & 7 & 8 & $39 \cdot 9$ & $1 \cdot 2$ & $8 \cdot 6$ & $11 \cdot 2$ & $5 \cdot 3$ & $33 \cdot 8$ & 0.66 & 3 & 3 & Cortisone (6) & $25 / 10 / 55$ \\
\hline (Table IX, Case 5) & 2 & 8 & 37 & $6 \cdot 6$ & $17 \cdot 1$ & $12 \cdot 2$ & $3 \cdot 8$ & $23 \cdot 3$ & 0.59 & 2 & 2 & Cortisone (12) & $6 / 10 / 55$ \\
\hline (Table IX, Case 10) & 1 & 8 & $33 \cdot 3$ & 3 & $15 \cdot 1$ & $14 \cdot 9$ & 3 & $30 \cdot 7$ & $0 \cdot 50$ & 2 & 2 & Prednisone (4) & $1 / 12 / 55$ \\
\hline $11 \ldots$ & 8 & $8 \cdot 4$ & $32 \cdot 7$ & $1 \cdot 9$ & $9 \cdot 8$ & $11 \cdot 1$ & $1 \cdot 8$ & $42 \cdot 7$ & 0.48 & 2 & 3 & Cortisone (48) & $22 / 10 / 55$ \\
\hline $12 \ldots \quad \ldots$ & 1 & 8 & $31 \cdot 8$ & $5 \cdot 5$ & $14 \cdot 5$ & $15 \cdot 5$ & $5 \cdot 9$ & $26 \cdot 8$ & 0.47 & 3 & 4 & Nil & $12 / 10 / 55$ \\
\hline $13 \ldots \quad \ldots$ & 3 & $7 \cdot 9$ & $31 \cdot 3$ & $6 \cdot 1$ & $15 \cdot 8$ & $13 \cdot 4$ & $5 \cdot 1$ & $28 \cdot 3$ & 0.45 & 3 & 5 & Nil & $25 / 10 / 55$ \\
\hline
\end{tabular}


TABLE VIII

RELATION OF DISEASE ACTIVITY TO SERUM PROTEIN CHANGES

\begin{tabular}{l|c|c|c|c|c|c}
\hline $\begin{array}{c}\text { Degree of } \\
\text { Disease } \\
\text { Activity }\end{array}$ & $\begin{array}{c}0 \\
\text { (Nil) }\end{array}$ & $\begin{array}{c}1 \\
\text { (Low) }\end{array}$ & $\begin{array}{c}2 \\
\text { (Marked) }\end{array}$ & $\begin{array}{c}3 \\
\text { (High) }\end{array}$ & Total \\
\hline \multirow{3}{*}{ Group } & I & 5 & 11 & 4 & 0 & 20 \\
\hline II & 0 & 6 & 12 & 1 & 19 \\
\hline Total & III & 0 & 1 & 7 & 5 & 13 \\
\hline
\end{tabular}

$1,2,4,11,14$, and 15 of Group II (Table VI); Case 5 of Group III (Table VII)). Some of these (Cases 11 and 15 of Group II; Case 5 of Group III) had been receiving cortisone for varying lengths of time but showed a tendency to relapse, and in them the true degree of disease activity was effectively demonstrated by the electrophoresis.

No typical electrophoretic pattern has yet been demonstrated (Ropes and others, 1954; Roy and six others, 1955) for rheumatoid arthritis as has been done, e.g., for cirrhosis of the liver and disseminated lupus erythematosus. Such patterns as have been found (Fig. 1, opposite) resemble those of disseminated lupus erythematosus, with a marked increase in the gamma globulin fraction, or else with a moderate but general increase in the alpha-2 globulin as in rheumatic fever or tuberculosis.

Functional Capacity.-No significant connexion was observed between the serum protein changes and functional capacity.

Hormone Therapy.-Appreciable serum protein changes were observed in 21 patients receiving treatment with cortisone, $\mathrm{ACTH}$, or prednisone; these were more marked with the two latter drugs. Table IX (overleaf) includes six cases from Group I $(2,4,6,11,12,18)$. Six cases from Group II $(1,7$, $8,9,15,17)$; four cases from Group III $(3,5,10,13)$; and five additional cases $(14,16,19,20,21)$.

The alpha-2 and particularly the gamma-2 globulin were the most sensitive to hormone treatment; the gamma globulin sometimes fell below the normal average, to half or even less than half the pre-treatment level. Fig. 2 (overleaf) shows the changes in Cases 6, 9, and 14 of Table IX.

In some cases which showed slight serum protein changes, long-term cortisone or ACTH appeared to have controlled the disease activity.

Of particular interest, however, are those patients with high disease activity and marked symptoms of inflammation, who were receiving large doses of hormone and in whom complications were encountered. In Cases 9 and 14 of Table IX a Cushing syndrome developed, and in Case 9 this was followed by steroid diabetes, haematemesis, melaena, and death. Cases 10 and 16 of Table IX developed active gastric ulcers, and Cases 8 and 15 of Table IX developed moon facies.

Cases 3 and 4 of Table IX developed bronchopneumonia with atypical symptomatology.

In these patients, particularly Cases $8,9,10,14$, 15 , and 16, the globulin fractions came down to normal, especially the gamma fractions, which in some instances even fell slightly below the normal average, although a corresponding fall in alpha-2 was not generally observed. Fig. 3 (overleaf) shows the changes in Case 14 of Table IX.

Table X (overleaf) shows the mean values of the last electrophoretic determinations recorded in Table IX for Cases 8, 9, 10, 14, 15, and 16.

Despite prolonged adrenocortical treatment, several patients showed marked and persistent hyperglobulinaemia with prevailing high gamma globulin; they also showed clinical signs of disease activity, such as pains, fever, loss of weight, and tendency to relapse (Cases 9, 10, 11, 12, 16, 17, 18, and 19 in Group II; Cases 1, 7, 9, and 11 of Group III).

A persistently high gamma globulin fraction despite prolonged adrenocortical treatment seems to indicate that the possibility of controlling the disease process is remote (Fig. 4, overleaf).

\section{Discussion}

Reticulo-endothelial hyperplasia is thought by some workers to play an essential part in the pathogenesis of rheumatoid arthritis (Curletto and Magistretti, 1949; Marmont, 1948; Wallis, 1950; Berglund and others, 1951; Layani and others, 1952). An inflammatory process which originates an ineffective antigen-antibody reaction, perhaps of auto-immune nature, is presumed to be the fundamental mechanism of this hyperplasia.

This process may comprise an inflammation of focal type (Albertini and Alb, 1947; MalaguzziValeri, 1955) inducing an altered reactivity. The appearance of amyloid, which is also found in rheumatoid arthritis, and has been attributed to the exhaustion of the reticulo-endothelial hyperplasia by prolonged stress (Teilum and Lindahl, 1954), also favours such a theory.

Hyperglobulinaemia is considered by some workers to be an expression of this hyperactivity (Berglund and others, 1951; Layani and others, 

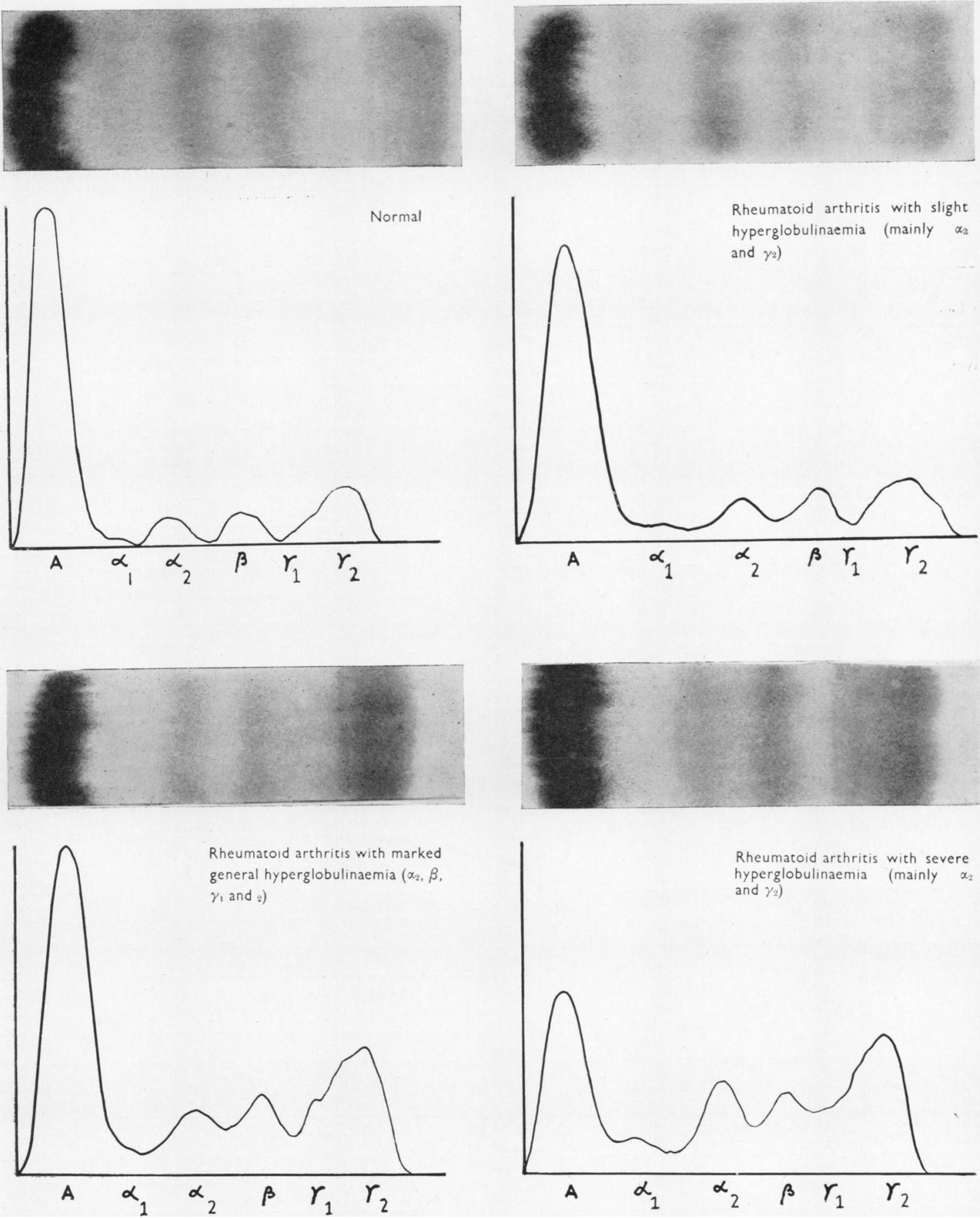

Fig. 1.-Paper electrophoresis of serum proteins and electrophoretic patterns in one normal subject and in three patients with rheumatoid arthritis. 


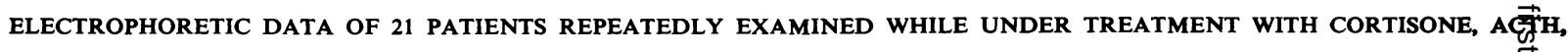

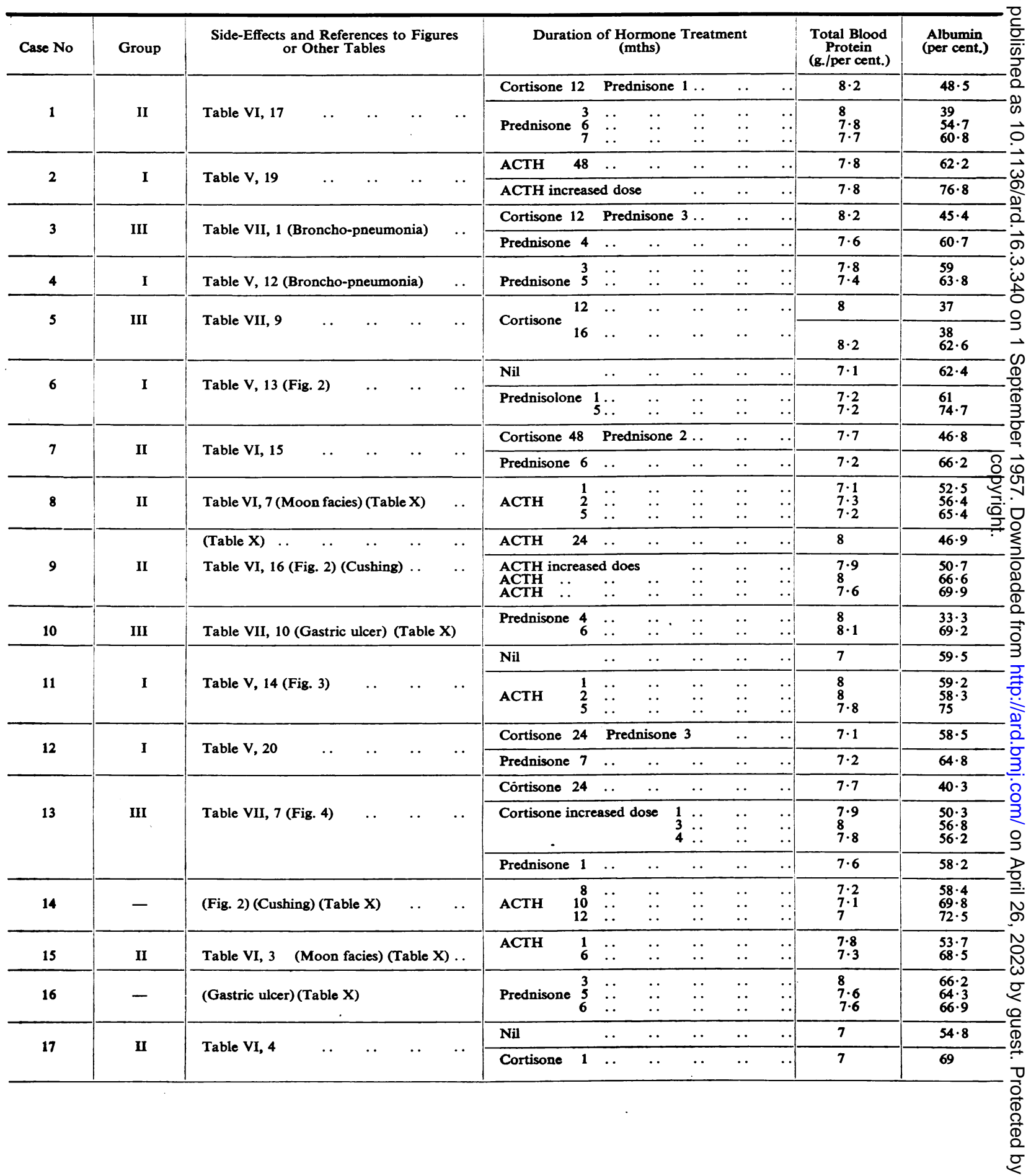


LB IX

AND PREDNISONE, SHOWING DURATION OF HORMONE TREATMENT AT DATE OF ELECTROPHORETIC EXAMINATION

\begin{tabular}{|c|c|c|c|c|c|c|c|c|}
\hline \multicolumn{5}{|c|}{ Globulin (per cent.) } & \multirow{2}{*}{$\underset{\text { Ratio }}{\text { A/G }}$} & \multirow{2}{*}{$\begin{array}{l}\text { Disease } \\
\text { Activity }\end{array}$} & \multirow{2}{*}{$\begin{array}{l}\text { Functional } \\
\text { Capacity }\end{array}$} & \multirow{2}{*}{$\begin{array}{c}\text { Date of } \\
\text { Examination }\end{array}$} \\
\hline$\alpha 1$ & $\alpha 2$ & $\beta$ & $\gamma 1$ & $\gamma 2$ & & & & \\
\hline $1 \cdot 8$ & $10 \cdot 8$ & $13 \cdot 1$ & $5 \cdot 1$ & $20 \cdot 7$ & 0.94 & 2 & 2 & $15 / 9 / 55$ Q \\
\hline $\begin{array}{l}3 \cdot 3 \\
2 \cdot 1 \\
3 \cdot 1\end{array}$ & $\begin{array}{l}9 \cdot 6 \\
7 \cdot 7 \\
7 \cdot 2\end{array}$ & $\begin{array}{r}13.9 \\
12.7 \\
8.8\end{array}$ & $\begin{array}{l}8 \cdot 7 \\
4 \cdot 8 \\
3 \cdot 2\end{array}$ & $\begin{array}{l}25 \cdot 5 \\
18 \cdot 1 \\
16 \cdot 7\end{array}$ & $\begin{array}{l}0 \cdot 63 \\
1 \cdot 19 \\
1 \cdot 59\end{array}$ & $\begin{array}{l}1 \\
1 \\
1\end{array}$ & $\begin{array}{l}2 \\
2 \\
2\end{array}$ & $\begin{array}{rll}10 / 11 / 55 & \cdots \\
2 / & 2 / 56 & \overrightarrow{0} \\
4 / 3 / 56 & 0\end{array}$ \\
\hline $2 \cdot 9$ & $12 \cdot 0$ & $11 \cdot 2$ & $1 \cdot 1$ & $10 \cdot 1$ & $1 \cdot 62$ & 1 & 1 & $2 / 1 / 56 \vec{\omega}$ \\
\hline $1 \cdot 5$ & $9 \cdot 6$ & $5 \cdot 1$ & $1 \cdot 5$ & $5 \cdot 5$ & $3 \cdot 30$ & 1 & 1 & 4/3/56 \% \\
\hline $5 \cdot 0$ & $15 \cdot 2$ & $10 \cdot 0$ & 1.9 & $22 \cdot 5$ & 0.83 & 3 & 3 & 13/10/55 으 \\
\hline $1 \cdot 2$ & $9 \cdot 9$ & $10 \cdot 1$ & $2 \cdot 7$ & $15 \cdot 3$ & $1 \cdot 55$ & 3 & 4 & $7 / 11 / 55 \vec{\sigma}$ \\
\hline $\begin{array}{l}2 \cdot 3 \\
0.9 \\
\end{array}$ & $\begin{array}{r}10 \cdot 2 \\
8.9 \\
\end{array}$ & $\begin{array}{l}10 \cdot 2 \\
10 \cdot 6 \\
\end{array}$ & $\begin{array}{l}1 \cdot 7 \\
2 \cdot 3 \\
\end{array}$ & $\begin{array}{l}16 \cdot 6 \\
13 \cdot 5 \\
\end{array}$ & $\begin{array}{l}1.43 \\
1.76 \\
\end{array}$ & $\begin{array}{l}1 \\
1\end{array}$ & 1 & $\begin{array}{l}20 / 10 / 55 \omega \\
13 / 12 / 55 \stackrel{\sim}{\omega} \\
\end{array}$ \\
\hline $6 \cdot 6$ & $17 \cdot 1$ & $12 \cdot 2$ & $3 \cdot 8$ & $23 \cdot 3$ & 0.59 & 2 & 2 & $6 / 10 / 550$ \\
\hline $\begin{array}{l}3 \cdot 5 \\
5 \cdot 2 \\
\end{array}$ & $\begin{array}{l}15 \cdot 2 \\
13 \cdot 7 \\
\end{array}$ & $\begin{array}{r}13.9 \\
5.8 \\
\end{array}$ & $\begin{array}{l}3 \cdot 3 \\
3 \cdot 2 \\
\end{array}$ & $\begin{array}{r}26 \cdot 1 \\
9 \cdot 5 \\
\end{array}$ & $\begin{array}{l}0.61 \\
1.67 \\
\end{array}$ & $\begin{array}{l}2 \\
1 \\
\end{array}$ & $\begin{array}{l}2 \\
1\end{array}$ & $\begin{array}{l}23 / 11 / 55 \mathrm{~J} \\
16 / 2 / 56 \quad \overrightarrow{\mathrm{c}}\end{array}$ \\
\hline $2 \cdot 4$ & $5 \cdot 7$ & $11 \cdot 3$ & $2 \cdot 5$ & $15 \cdot 7$ & $1 \cdot 63$ & 2 & 3 & $20 / 10 / 55 \frac{D}{0}$ \\
\hline $\begin{array}{l}0.8 \\
0.9\end{array}$ & $\begin{array}{l}10 \cdot 1 \\
12 \cdot 1\end{array}$ & $\begin{array}{c}10 \\
4 \cdot 5\end{array}$ & $\begin{array}{l}1.1 \\
0.6\end{array}$ & $\begin{array}{c}17 \\
9 \cdot 2\end{array}$ & $\frac{1 \cdot 52}{3}$ & 1 & 2 & 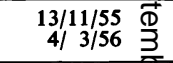 \\
\hline $3 \cdot 1$ & $9 \cdot 4$ & $15 \cdot 3$ & $6 \cdot 0$ & $19 \cdot 4$ & 0.88 & 1 & 2 & $14 / 11 / 55 \stackrel{\Phi}{\longrightarrow}$ \\
\hline $2 \cdot 2$ & $12 \cdot 4$ & 9 & $1 \cdot 6$ & $8 \cdot 6$ & 1.95 & 0 & 1 & $2 / 3 / 58 \overrightarrow{0} \overrightarrow{0}$ \\
\hline $\begin{array}{l}4 \cdot 2 \\
3.9 \\
0.5 \\
\end{array}$ & $\begin{array}{r}10 \cdot 3 \\
10 \cdot 3 \\
7 \cdot 9 \\
\end{array}$ & $\begin{array}{l}15 \cdot 3 \\
15 \cdot 5 \\
12 \cdot 3 \\
\end{array}$ & $\begin{array}{l}3 \cdot 1 \\
4 \cdot 1 \\
1 \cdot 3 \\
\end{array}$ & $\begin{array}{r}14 \cdot 6 \\
9 \cdot 7 \\
12 \cdot 6 \\
\end{array}$ & $\begin{array}{l}1 \cdot 10 \\
1 \cdot 29 \\
1 \cdot 85\end{array}$ & $\begin{array}{l}2 \\
2 \\
1\end{array}$ & $\begin{array}{l}3 \\
3 \\
2\end{array}$ & 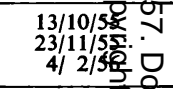 \\
\hline $3 \cdot 9$ & $18 \cdot 2$ & $13 \cdot 8$ & $2 \cdot 1$ & $15 \cdot 1$ & 0.88 & 2 & 1 & $20 / 10 / 55 \leqq$ \\
\hline $\begin{array}{l}5 \cdot 6 \\
3 \cdot 3 \\
2 \cdot 2 \\
\end{array}$ & $\begin{array}{r}13 \cdot 3 \\
9 \cdot 9 \\
10 \cdot 3 \\
\end{array}$ & $\begin{array}{r}15 \cdot 1 \\
11.4 \\
7.4 \\
\end{array}$ & $\begin{array}{l}3 \cdot 8 \\
2 \cdot 3 \\
0 \cdot 5 \\
\end{array}$ & $\begin{array}{r}11 \cdot 5 \\
6 \cdot 5 \\
9 \cdot 7 \\
\end{array}$ & $\begin{array}{l}1.03 \\
1.99 \\
2.31 \\
\end{array}$ & $\begin{array}{l}2 \\
2 \\
2\end{array}$ & $\begin{array}{l}1 \\
2 \\
2\end{array}$ & $\begin{array}{rr}4 / 11 / 55 & \bar{O} \\
25 / 11 / 55 & 0 \\
4 / 2 / 56 & \stackrel{\circ}{\circ} \\
\end{array}$ \\
\hline $\begin{array}{l}3.9 \\
1.9\end{array}$ & $\begin{array}{c}15 \cdot 1 \\
8\end{array}$ & $\begin{array}{r}14.9 \\
8.8 \\
\end{array}$ & $\begin{array}{l}3 \\
1 \cdot 4\end{array}$ & $\begin{array}{l}30 \cdot 7 \\
10 \cdot 7 \\
\end{array}$ & $\begin{array}{l}0 \cdot 50 \\
2 \cdot 24 \\
\end{array}$ & $\begin{array}{l}2 \\
1\end{array}$ & $\begin{array}{l}2 \\
2 \\
\end{array}$ & 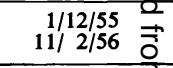 \\
\hline $4 \cdot 3$ & $9 \cdot 3$ & $9 \cdot 1$ & $1 \cdot 3$ & $16 \cdot 5$ & $1 \cdot 48$ & 2 & 2 & $15 / 10 / 55 \frac{3}{2}$ \\
\hline $\begin{array}{l}2 \cdot 2 \\
2 \cdot 2 \\
2 \cdot 4\end{array}$ & $\begin{array}{l}8 \\
8 \cdot 7 \\
5 \cdot 1\end{array}$ & $\begin{array}{r}13 \cdot 3 \\
11 \cdot 2 \\
9 \cdot 7\end{array}$ & $\begin{array}{l}5 \cdot 5 \\
5 \cdot 5 \\
2\end{array}$ & $\begin{array}{r}11 \cdot 8 \\
14 \cdot 1 \\
5 \cdot 8\end{array}$ & $\begin{array}{l}1.45 \\
1 \cdot 39 \\
3\end{array}$ & $\begin{array}{l}2 \\
2 \\
1\end{array}$ & $\begin{array}{l}2 \\
2 \\
1\end{array}$ & $\begin{array}{r}\text { 14/11/55 } \\
2 / 12 / 55 \\
\text { 4/3/56 } \\
\end{array}$ \\
\hline $2 \cdot 1$ & $13 \cdot 8$ & $10 \cdot 4$ & $2 \cdot 3$ & $12 \cdot 9$ & $1 \cdot 44$ & 2 & 3 & 13/11/55 은 \\
\hline $3 \cdot 7$ & $9 \cdot 9$ & $11 \cdot 4$ & $1 \cdot 9$ & $8 \cdot 3$ & $1 \cdot 83$ & 2 & 3 & $1 / 3 / 56 \quad 3$ \\
\hline 2 & $9 \cdot 9$ & $8 \cdot 7$ & $5 \cdot 3$ & $33 \cdot 8$ & 0.67 & 3 & 2 & 6/10/55 ฉृ \\
\hline $\begin{array}{l}2 \cdot 2 \\
1 \cdot 2 \\
3 \cdot 3 \\
\end{array}$ & $\begin{array}{l}7 \\
3 \cdot 6 \\
7 \cdot 4 \\
\end{array}$ & $\begin{array}{l}7 \\
4 \cdot 4 \\
5 \cdot 5 \\
\end{array}$ & $\begin{array}{l}4 \\
2 \cdot 4 \\
3 \cdot 2 \\
\end{array}$ & $\begin{array}{l}29 \cdot 5 \\
31 \cdot 6 \\
24.4 \\
\end{array}$ & $\begin{array}{l}1.31 \\
1 \cdot 26 \\
\end{array}$ & $\begin{array}{l}2 \\
2 \\
3 \\
\end{array}$ & $\begin{array}{l}2 \\
2 \\
2\end{array}$ & 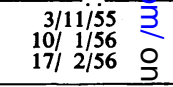 \\
\hline $1 \cdot 6$ & $6 \cdot 4$ & 6.9 & $6 \cdot 7$ & $20 \cdot 2$ & $1 \cdot 38$ & 2 & 2 & $2 / 3 / 56 \frac{D}{0}$ \\
\hline $\begin{array}{l}2 \cdot 4 \\
2 \cdot 3 \\
2 \cdot 2\end{array}$ & $\begin{array}{l}9 \cdot 6 \\
6 \cdot 5 \\
4 \cdot 6\end{array}$ & $\begin{array}{c}11 \\
9 \\
12 \cdot 5\end{array}$ & $\begin{array}{l}2 \cdot 2 \\
2 \cdot 6 \\
0.6\end{array}$ & $\begin{array}{r}16 \cdot 2 \\
10 \cdot 3 \\
7 \cdot 6\end{array}$ & $\begin{array}{l}1 \cdot 42 \\
2 \cdot 32 \\
2 \cdot 53\end{array}$ & $\begin{array}{l}2 \\
1 \\
1\end{array}$ & $\begin{array}{l}2 \\
2 \\
2\end{array}$ & $\begin{array}{rl}12 / 10 / 55 & \equiv \\
1 / 12 / 55 & N \\
4 / 2 / 56 & \text { م } \\
\end{array}$ \\
\hline $\begin{array}{l}1 \cdot 3 \\
2 \cdot 3 \\
\end{array}$ & $\begin{array}{l}12 \cdot 8 \\
10\end{array}$ & $\begin{array}{r}11.9 \\
8.5 \\
\end{array}$ & 2.7 & $\begin{array}{l}18 \cdot 3 \\
10\end{array}$ & $\begin{array}{l}1 \cdot 13 \\
2 \cdot 10 \\
\end{array}$ & 2 & $\begin{array}{l}3 \\
2 \\
\end{array}$ & $\begin{array}{rl}24 / 9 / 55 & \mathrm{~N} \\
1 / 2 / 56 & \mathrm{~N} \\
\end{array}$ \\
\hline $\begin{array}{l}1 \\
0.8 \\
1.7 \\
\end{array}$ & $\begin{array}{r}8 \cdot 3 \\
9 \\
12 \cdot 9 \\
\end{array}$ & $\begin{array}{r}10 \cdot 7 \\
10 \cdot 7 \\
9 \cdot 8 \\
\end{array}$ & $\begin{array}{l}2 \cdot 1 \\
1.8 \\
0.9 \\
\end{array}$ & $\begin{array}{r}11 \cdot 7 \\
13.4 \\
7.8 \\
\end{array}$ & $\begin{array}{l}1.93 \\
1.83 \\
1.94\end{array}$ & $\begin{array}{l}2 \\
2 \\
1\end{array}$ & $\begin{array}{l}3 \\
2 \\
1\end{array}$ & $\begin{array}{ll}24 / 11 / 55 & \sigma \\
19 / 1 / 56 & \underset{<}{18 / 2 / 56}\end{array}$ \\
\hline $4 \cdot 2$ & $10 \cdot 3$ & $16 \cdot 3$ & $4 \cdot 2$ & $10 \cdot 2$ & $1 \cdot 20$ & 1 & 2 & $13 / 10 / 55 \bar{\Phi}$ \\
\hline 1.6 & 6.9 & 11 & $2 \cdot 8$ & $8 \cdot 7$ & $2 \cdot 20$ & 1 & 1 & $3 / 12 / 55 \div$ \\
\hline
\end{tabular}




\begin{tabular}{|c|c|c|c|c|c|c|c|c|c|c|c|c|c|}
\hline \multirow{2}{*}{$\begin{array}{c}\text { Case No. } \\
18\end{array}$} & \multirow{2}{*}{ Group } & \multicolumn{4}{|c|}{$\begin{array}{l}\text { Side-Effects and References to Figures } \\
\text { or Other Tables }\end{array}$} & \multicolumn{6}{|c|}{ Duration of Hormone Treatment } & \multirow{2}{*}{$\begin{array}{c}\begin{array}{c}\text { Total Blood } \\
\text { Protein } \\
\text { (g./per cent.) }\end{array} \\
7 \cdot 5 \\
7 \cdot 8\end{array}$} & \multirow{2}{*}{ 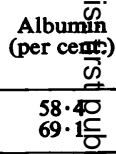 } \\
\hline & & Table V, 11 & .. & .. & $\cdots$ & $\begin{array}{ll}\text { Prednisone } & 1 \\
6\end{array}$ & $\begin{array}{l}. \\
\cdots\end{array}$ & $\therefore$ & . & 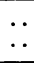 &.. & & \\
\hline \multirow{2}{*}{19} & \multirow{2}{*}{ - } & \multirow[t]{2}{*}{ Hypoglobulinaemia } & \multirow[t]{2}{*}{.. } & \multirow{2}{*}{ * } & \multirow{2}{*}{$\cdots$} & Cortisone 48 & Predni & isone 2 & & $\ldots$ & $\ldots$ & $7 \cdot 9$ & $66 \cdot 8 \overline{n^{2}}$ \\
\hline & & & & & & Prednisone 5 & $\ldots$ & $\ldots$ & $\ldots$ & .. & $\ldots$ & 8 & $76 \cdot 6 \frac{1}{2}$ \\
\hline 20 & - & Slight side-effects .. &.. & $\ldots$ & $\ldots$ & Cortisone $\begin{array}{l}24 \\
26\end{array}$ & $\because$ & $\because$ & $\ldots$ & $\ldots$ &.. & $7 \cdot 4$ & $53.4^{0}$ \\
\hline \multirow{2}{*}{21} & \multirow{2}{*}{ - } & \multirow[t]{2}{*}{ Recurrent side-effects } & \multirow[t]{2}{*}{. } & \multirow[t]{2}{*}{.. } & \multirow[t]{2}{*}{.. } & Cortisone 24 & ACTH & 3 & .. & .. & .. & $7 \cdot 9$ & $64 \cdot 5^{\circ}$ \\
\hline & & & & & & ACTH & $\ldots$ & .. & . & . &. & $8 \cdot 1$ & $59 \cdot \vec{w}$ \\
\hline
\end{tabular}

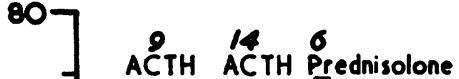

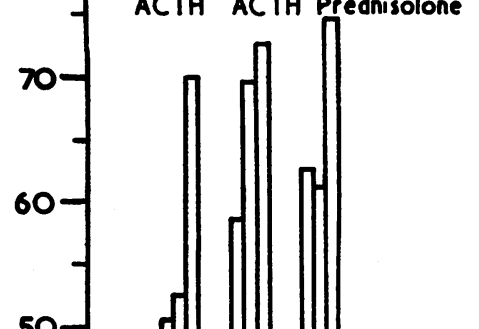

50

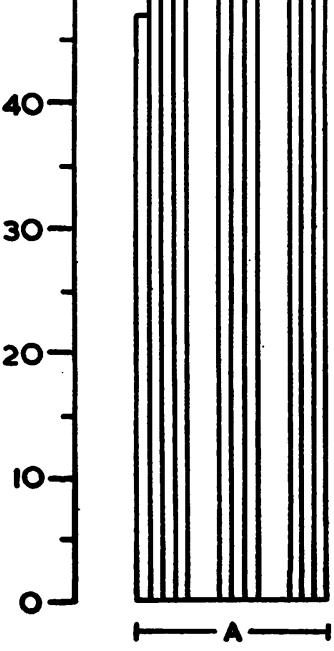

TABLE X

MEAN VALUES IN SIX PATIENTS WITH DISEASE ACTIVITY WHO DEVELOPED COMPLICATIONS WHILE RECEIVING HORMONE THERAPY

\begin{tabular}{|c|c|c|c|c|c|c|c|}
\hline \multirow{2}{*}{$\underset{\text { (per cent.) }}{\text { Albumin }}$} & \multicolumn{5}{|c|}{ Globulin (per cent.) } & \multirow{2}{*}{$\begin{array}{c}\text { A/G } \\
\text { Ratio }\end{array}$} & \multirow{2}{*}{$\begin{array}{c}\text { Total } \\
\text { Protein } \\
\text { Blood } \\
\text { (g./100ml.) }\end{array}$} \\
\hline & $\alpha 1$ & $\alpha 2$ & $B$ & $\gamma 1$ & $\gamma^{2}$ & & \\
\hline $68 \cdot 7$ & $1 \cdot 8$ & 9 & 9.9 & 0.9 & $9 \cdot 7$ & $2 \cdot 14$ & $7 \cdot 4$ \\
\hline
\end{tabular}

Fig. 2. Serum protein changes in three patients during hormone treatment of rheumatoid arthritis (Table IX). The first and the second group of columns relate to Cases 9 and 14 (ACTH), and the third to Case 6 (prednisone). The columns represent readings taken on successive dates as follows:

Case 9. October 20, 1955

November 4, 1955

November 25, 1955

February 4, 1956
Case 14: October 12, 1955

December 1, 1955

February 4, 1956
Case 6: October 20, 1955

November 13, 1955

March 4, 1956
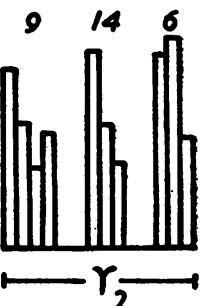
I(continued)

\begin{tabular}{|c|c|c|c|c|c|c|c|c|}
\hline \multicolumn{5}{|c|}{ Globulin (per cent.) } & \multirow{2}{*}{$\begin{array}{c}\text { A/G } \\
\text { Ratio }\end{array}$} & \multirow{2}{*}{$\begin{array}{l}\text { Disease } \\
\text { Activity }\end{array}$} & \multirow{2}{*}{$\begin{array}{c}\text { Functional } \\
\text { Capacity }\end{array}$} & \multirow{2}{*}{$\begin{array}{c}\text { Date of } \\
\text { Examination }\end{array}$} \\
\hline$\alpha 1$ & $\alpha 2$ & $B$ & $\gamma 1$ & $\gamma 2$ & & & & \\
\hline $2 \cdot 5$ & $\begin{array}{r}10 \cdot 1 \\
4 \cdot 3\end{array}$ & 11 & $\begin{array}{l}2 \cdot 1 \\
0 \cdot 9\end{array}$ & $\begin{array}{l}16 \cdot 2 \\
14 \cdot 2\end{array}$ & $\begin{array}{l}1 \cdot 42 \\
2 \cdot 30\end{array}$ & $\begin{array}{l}1 \\
1\end{array}$ & 2 & $\begin{array}{r}20 / 9 / 55 \\
4 / 2 / 56\end{array}$ \\
\hline $3 \cdot 1$ & $9 \cdot 9$ & $10 \cdot 6$ & $2 \cdot 3$ & $7 \cdot 3$ & 2 & 2 & 4 & $5 / 10 / 55$ \\
\hline $1 \cdot 4$ & $7 \cdot 2$ & $9 \cdot 4$ & 0.9 & $4 \cdot 5$ & $3 \cdot 15$ & 2 & 4 & $5 / 1 / 56$ \\
\hline $\begin{array}{l}1 \cdot 9 \\
1 \cdot 7\end{array}$ & $\begin{array}{r}11 \cdot 6 \\
9 \cdot 2\end{array}$ & $\begin{array}{l}16 \cdot 8 \\
17 \cdot 1\end{array}$ & $\begin{array}{l}1 \cdot 8 \\
1 \cdot 5\end{array}$ & $\begin{array}{l}14 \cdot 9 \\
11 \cdot 1\end{array}$ & $\begin{array}{l}1 \cdot 12 \\
1 \cdot 48\end{array}$ & $\begin{array}{l}1 \\
1\end{array}$ & $\begin{array}{l}1 \\
1\end{array}$ & $\begin{array}{r}24 / 11 / 55 \\
1 / 2 / 56\end{array}$ \\
\hline $1 \cdot 5$ & $9 \cdot 7$ & $5 \cdot 7$ & $1 \cdot 9$ & $16 \cdot 7$ & $1 \cdot 80$ & 2 & 2 & $6 / 10 / 55$ \\
\hline $4 \cdot 9$ & $9 \cdot 6$ & $9 \cdot 5$ & $1 \cdot 9$ & $14 \cdot 8$ & $1 \cdot 49$ & 2 & 2 & $10 / 11 / 55$ \\
\hline
\end{tabular}

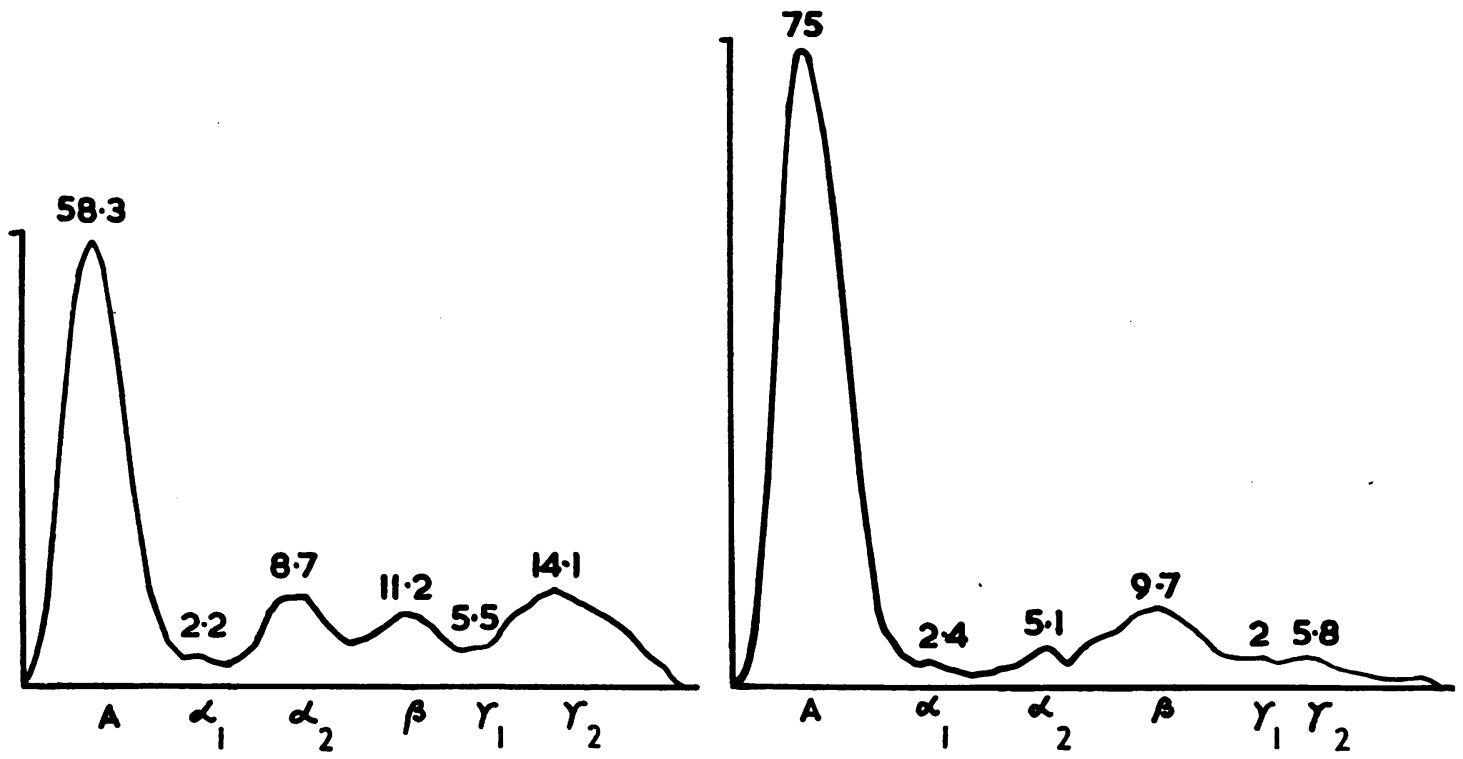

Fig. 3.-Electrophoretic patterns on December 2, 1955, and March 4, 1956, in a case of rheumatoid arthritis (Case 11, Table IX), after 2 months' and 5 months' treatment with ACTH, while developing marked hyperadrenocorticalism (Cushing's syndrome).

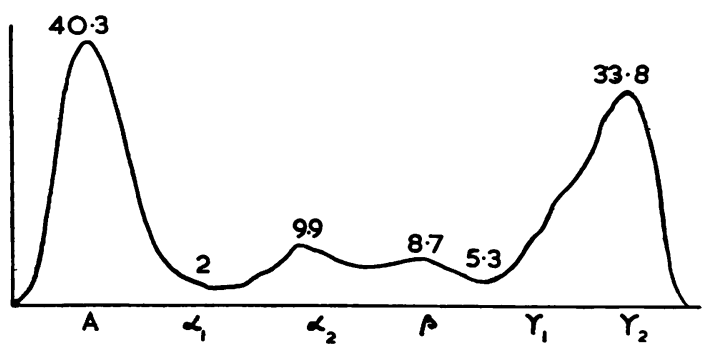

Fig. 4.-Electrophoretic pattern in a case of rheumatoid arthritis (Case 7, Table VII), showing severe hyperglobulinaemia after 2 years' treatment with cortisone.

1952; Bianchi, 1953; Caniggia, 1955), since globulin and antibodies originate in the reticulo-endothelial system and mainly from the plasmocytes (Fagraeus,
1948). The increase in the gamma globulin fraction, where antibodies are most prevalent (Tiselius and Kabat, 1939), is closely related to plasmocytic hyperplasia (Ehrich, Drabkin, and Forman, 1949), a plasmocyte being defined as "the morphological expression of a reticular cell at its maximum of antibody formation" (Fagraeus, 1948). Other factors in rheumatoid hyperglobulinaemia are:

(i) An appreciable amount of the gamma-1 fraction, with hyperimmune and perhaps auto-immune significance (Wallis, 1950; Layani and others, 1952);

(ii) The positivity of various serum-agglutinating reactions (Berglund and others, 1951);

(iii) The increasingly frequent discovery of amyloid 
changes (Teilum and Lindahl, 1954; Fearnley and Lackner, 1955).

Amyloidosis has been reported in several hyperglobulinaemic conditions with prolonged reticuloendothelial hyperactivity (Teilum and Lindahl, 1954), and has been related to an immunological mechanism, also of auto-immune type, by Ritama and Saksela (1949).

Other points, apart from the gamma-1 fraction (Wallis, 1950; Layani and others, 1952), in favour of an auto-immune mechanism in rheumatoid arthritis are positive results with the Coombs test (Gear and Zoutendyk, 1953), and recent data on L.E. cells (Kievits, Goslings, Schuit, and Hijmans, 1956); the percentage incidence of the latter is similar (17 and 16 per cent. respectively).

Hormone therapy acts on the mesenchymal tissues particularly by depressing this reticuloendothelial hyperactivity (Villa, Ballabio, and Sala, 1953; Berglund and others, 1951), but it cannot modify the unknown basic process which promotes it.

Joint alterations frequently occur in dysproteinaemic diseases such as myelomatosis, amyloidosis (Chini, 1933; Poli, 1951), and disseminated lupus erythematosus (Duthie and Davidson, 1955; Malaguzzi-Valeri, 1955).

Reticulo-endothelial hyperactivity may involve the joint tissues, causing the formation of amyloid and influencing the serum protein balance (Justin-Besancon, Rubens-Duval, and Neumann, 1949; Chini, 1950); intra-articular hyperglobulinaemia has been found in patients with severe rheumatoid arthritis of long standing (Perlmann, Ropes, Kaufman, and Bauer, 1954). On the other hand, marked synovial plasmocytic reactions related to an allergic mechanism have been reported by Chini (1933) and hypertrophic osteo-arthropathy showing synovial congestion and lymphocytic infiltration has been described by Lucherini (1954).

Hyperglobulinaemia might cause more severe joint involvement by vascular modifications (Eckerström, 1948), or by increased capillary permeability (Perlmann and others, 1954). Or it may cause further damage by using up the materials needed for albumin and haemoglobin synthesis (Wallis, 1950), and by developing the formation of auto-antibodies (generically of antimesenchymal type), so inducing the pattern of a self-maintaining disease (Dausset, 1953; Scheiffarth and Bulitta, 1953; Malaguzzi-Valeri, 1955).

The following characteristics support this theory of the pathogenesis of rheumatoid arthritis:

(1) The marked rise in the gamma globulin fraction (acknowledged to be of antibody function), and also in the gamma-1 globulin fraction (of hyper- immune significance), both resulting from reticuloendothelial hyperactivity.

(2) The return to normal of hyperglobulinaemia after hormone treatment, together with the favourable clinical progress of the disease.

(3) Persistent serum protein changes, mainly represented by a rise in the gamma globulin fraction, which may be accompanied in severe cases by marked joint symptoms resistant to long-term hormone therapy.

(4) The persistently raised alpha-2 globulin fraction not corresponding to the fall in gamma globulin in cases with high disease activity and complications due to secondary hyperadrenalism.

\section{Summary}

The serum protein pattern in 56 patients with rheumatoid arthritis and one with ankylosing spondylitis was investigated by paper electrophoresis.

A significant correspondence was observed between the degree of systemic disease activity and the changes in the electrophoretic patterns.

These changes comprised varying increases in the alpha globulin fraction (particularly alpha-2), marked increases in the gamma globulin fraction (particularly gamma-2), and a more or less marked fall in the albumin fraction.

Seven patients with osteo-arthritis showed no characteristic serum protein changes.

The electrophoretic data were observed in 21 patients receiving treatment with ACTH, cortisone, and prednisone; a close correspondence was seen between favourable clinical progress and a return of the electrophoretic pattern to normal. Persistent serum protein changes, more frequently represented by increased gamma globulin fractions, were associated with a poor prognosis.

Marked serum protein changes, particularly a marked fall in the gamma globulin fraction, were observed in six cases presenting hyperadrenocortical complications.

An underlying alteration in reactivity is presumed to promote reticulo-endothelial hyperactivity, expressed by the hyperimmune characteristics of the hyperglobulinaemia.

Different relationships between this altered reactivity and the mesenchymal reaction may account for the great variety of clinical and proteinaemic manifestations of rheumatoid arthritis and the widely different results of hormone therapy in different patients.

It is suggested that the derangement of this reticulo-endothelial activity may lead to the development of a self-maintaining disease process. 
I am especially grateful to Dr. W. S. C. Copeman and Dr. Oswald Savage for their advice and encouragement, and to Dr. L. Chapman for his constant help.

\section{REFERENCES}

Albertini, A. von, and Alb, O. (1947). Cardiologia (Basel), 12, 133. Berglund, K., Nordenson, N. G., and Olhagen, B. (1951). Acto endocr. (Kbh.), 8, 1.

Bianchi, V. (1953). Reumatismo, 5, 158.

Caniggia, A. (1955). G. Mal. infett. parassit., 7, 113.

Chini, V. (1933). Boll. Ist. Sier. Milan, 12, 657.

(1950). Rev. Rhum., 17, 335.

Curletto, R., and Magistretti, F. (1949). Haematologica, 33, 529.

Dausset, J. (1953). Schweiz. med. Wschr., 83, 1037.

Duthie, J. J. R., and Davidson, L. S. P. (1955). In"Text-book of the Rheumatic Diseases", ed. W. S. C. Copeman, 2nd ed., p. 185 Livingstone, Edinburgh.

Eckerström, S. (1948). Acta med. scand., 132, 20.

Ehrich, W. E., Drabkin, D. L., and Forman, C. (1949). J. exp. Med., 90, 157 .

Fagraeus, A. (1948). Acta med. scand., Suppl. 204.

Fearnley, G. R., and Lackner, R. (1955). Brit. med. J., 1, 1129.

Flynn, F. V., and De Mayo, P. (1951). Lancet, 2, 235.

Gear, J., and Zoutendyk, A. (1953). Minerva med. (Torino) (Parte Sci.), 44, (1) 473 .

Gubner, R. (1951). Amer. J. med. Sci., 221, 169.

Hävermark, N. G., and Nordenson, N. G. (1953). Acta haemat. (Basel), 9, 227.

Hunt, T. E., and Trew, J. A. (1954). Annals of the Rheumatic Diseases, 13, 201.

Jacqueline, F., Traverse, P. M. de, and Besson, L. (1954). Rev. Rhum., 21, 329.

Justin-Besancon, L., Rubens-Duval, A., and Neumann, G. (1949). Ibid., 16, 547 .

Kievits, G. H., Goslings, J., Schuit, H. R. E., and Hijmans, W. (1956). Annals of the Rheumatic Diseases, 15, 211

Layani, F., Bengui, A., and De Mende, S. (1952). Sem. Hôp. Paris, 28,3221 .

Lucherini, T. (1954). Reumatismo, 6, (Suppl. to fasc. 3), p. 16.

Malaguzzi-Valeri, C. (1955). "Le malattie del collageno", p. 102 Il Pensiero Scientifico-Edit., Rome.

Marmont, A. (1948). Arch. "Maragliano"; Patol. Clin., 3, 1289.

Olhagen, B. (1952). In "Rheumatic Diseases", based on Proc. VII Int. Congr. Rheum. Dis., p. 365. Saunders, Philadelphia.

Perlmann, G. E., Ropes, M. W., Kaufman, D., and Bauer, W. (1954). J. clin. Invest., 33, 319.

Poli, E. (1951). "Fisiopatologia e clinica del protidoplasma", pp. 552-614-722. Delfino, Milan.

Reiner, M. (1950). Proc. Soc. exp. Biol., 74, 529.

Ritama, V., and Saksela, N. (1949). Ann. Med. intern. Fenn., 38, 188. (Abs. in (1951). Excerpta med. (Sect. 6, Intern. Med.) 5, 273.)

Ropes, M. W., Perlmann, G. E., Kaufman, D., and Bauer, W. (1954). J. clin. Invest., 33, 311 .

Roy, L. M. H., Wigzell, F. W., Demers, R., Sinclair, R. J. G., Duthie, J. J. R., Atherden, S. M., and Marrian, G. F. (1955). Annals of the Rheumatic Diseases, 14, 183.

Scheiffarth, F., and Bulitta, A. (1953). Dtsch. med. Wschr., 78, 948. Teilum, G., and Lindahl, A. (1954). Acta med. scand., 149, 449.

Tiselius, A., and Kabat, E. A. (1939). J. exp. Med., 69, 119

Van Leeuwen, G. J., Kelly, H. G., and Jackson, R. L. (1955). A.M.A. Amer. J. Dis. Child., 89, 304.

Villa, L., Ballabio, C. B., and Sala, G. (1953). Relazione VI Congresso Soc. Ital. Reumatologia. Reumatismo, 5, (Suppl. fasc. 2), p. 43.

Wallis, A. D. (1950). Ann. intern. Med., 32, 63.

Wolfson, W. Q., Cohn, C., Calvary, E., and Ichiba, F. (1948). Amer. J. clin. Path., 18, 723 .

\section{Hyperglobulinémie dans l'arthrite rhumatismale \\ RÉSUMÉ}

On a étudié par électrophorèse sur papier la disposition de la protéine sérique chez 56 malades atteints d'arthrite rhumatismale et un atteint de spondylarthrite ankylosante.

On a observé une correspondance significative entre le degré d'activité de la maladie et les altérations de la disposition électrophorétique.

Ces altérations comprenaient des augmentations variées de la fraction alpha (en particulier alpha-2) de la globuline, des augmentations marquées de la fraction gamma (en particulier gamma-2) de la globuline et une diminution marquée de la fraction de l'albumine.

Sept malades atteints d'ostéoarthrite ne révélèrent pas d'altérations caractéristiques de la protéine sérique.

Les données électrophorétiques furent étudiées chez 21 malades soumis à un traitement d'ACTH, cortisone et prednisone; on constata une correspondance étroite entre un progrès clinique favorable et un retour de la disposition électrophorétique normale. Des altérations persistantes de la protéine sérique, le plus souvent représentées par une augmentation des fractions gamma, indiquaient une prognose peu favorable.

Des altérations prononcées de la protéine sérique, surtout une chute marquée de la fraction gamma de la globuline, furent observées dans six cas présentant des complications hypersurréno-corticales.

On suppose qu'un processus dysergique sous-jacent favorise l'hyperactivité réticulo-endothéliale, exprimée par les caractères hyperimmuns de l'hyperglubulinémie.

Des relations différentes entre ce processus dysergique et la réaction mésenchymateuse peuvent expliquer la grande variété de manifestations cliniques et protéinémiques de l'arthrite rhumatismale et les résultats si différents de la thérapie hormonale chez les différents malades.

On suggère que cette hyperactivité réticulo-endothéliale peut précipiter un processus morbide qui, ensuite, se maintiendrait tout seul.

\section{Hiperglobulinemia en la artritis reumatoide SUMARIO}

Se estudió por electroforesis sobre papel la disposición de la proteina sérica en 56 enfermos con artritis reumatoide y uno con espondilartritis anquilosante.

So observó una correspondencia significativa entre el grado de actividad mórbida y las alteraciones de la disposición electroforética.

Estas alteraciones comprendieron varias aumentaciones de la fracción alfa (en particular alfa-2) de la globulina, aumentaciones marcadas de la fracción gama (en particular gama-2) de la globulina y una disminución marcada de la fracción albumínica.

Siete enfermos con ósteoartritis no revelaron alteraciones características de la proteina sérica.

Los datos electroforéticos fueron estudiados en 2I enfermos tratados con ACTH, cortisona y prednisona ; se halló una correspondencia estrecha entre un progreso clínico favorable y un retorno de la disposición electroforética normal. Alteraciones persistentes de la proteina sérica, lo más frecuentemente representadas por un aumento de la fracción gama, indicaban una prognosis poco favorable.

Alteraciones pronunciadas de la proteina sérica particularmente una caida mercada de la fracción gama de la globulina, fueron observadas en seis casos con complicaciones hipersuprarreno-corticales.

Se supone que un proceso disérgico subyacente favorece la hiperactividad retículo-endotelial, expresada por los rasgos hiperimunos de la hiperglobulinemia.

Relaciones diferentes entre este proceso disérgico y la reacción mesenquimatosa pueden explicar la gran variedad de manifestaciones clínicas y proteinémicas de la artritis reumatoide y los resultados sumamente diferentes de la terapia hormonal en diferentes enfermos.

Se sugiere que esta hiperactividad retículo-endotelial puede llevar a un proceso mórbido que luego pudiera mantenerse por si mismo. 